\title{
CHARACTERISTICS OF HYDROXAMIC ACID INDUCTION IN WHEAT TRIGGERED BY APHID INFESTATION
}

\author{
ERNESTO GIANOLI* and HERMANN M. NIEMEYER \\ Departamento de Ciencias Ecológicas \\ Facultad de Ciencias, Universidad de Chile \\ Casilla 653, Santiago, Chile
}

(Received February 5, 1997; accepted July 30, 1997)

\begin{abstract}
Hydroxamic acids $(\mathrm{Hx})$ are natural products of Gramineae that are associated with cereal resistance to pests. We aimed at characterizing the induction of $\mathrm{Hx}$ accumulation in seedlings of wheat, Triticum aestivum, by short-term infestation of the cereal aphid, Rhopalosiphum padi. A load of 25 aphids increased significantly the $\mathrm{Hx}$ levels in the infested primary leaf in comparison with control levels. Lower loads did not increase Hx concentration. Aphid infestation lasting $16 \mathrm{hr}$ did not elicit induction of $\mathrm{Hx}$, even after a time-lag of $32 \mathrm{hr}$ to allow the expression of any induced response. Fortyeight hours was the minimum duration of aphid infestation required to trigger $\mathrm{Hx}$ induction. The age of the infested tissue (the primary leaf) did not affect induction. Similar increases of $\mathrm{Hx}$ were found in unfolding, expanding, and totally expanded primary leaves. It was determined that the regime of nutrient supply ( $\mathrm{N}$-intensive nutritive solutions at low and high concentration) to wheat seedlings had no effect on the magnitude of the aphid-induced $\mathrm{Hx}$ (N-based secondary metabolites). Results obtained are discussed in the framework of general theories of plant defense allocation.
\end{abstract}

Key Words-Defense, herbivory, aphids, wheat, Gramineae, hydroxamic acids, Defense theory, Carbon/Nutrient theory.

\section{INTRODUCTION}

The last decade has seen a considerable increase in the number of reports on herbivory-induced phytochemical responses. However, seldom have these induced responses (IR) been subjected to a comprehensive characterization in

*To whom correspondence should be addressed. 
terms of mechanisms, spatial and temporal dynamics, biotic and abiotic constraints to their expression, and associated costs imposed to the plant. Outstanding exceptions to this generalization come from the works on IR of wild tobacco alkaloids (Baldwin, 1989; Baldwin et al., 1990) and wild parsnip furanocoumarins (Zangerl, 1990; Zangerl and Berenbaum, 1995). Although work on IR has mainly addressed questions regarding theoretical issues such as optimal patterns of defense allocation (Ohnmeiss and Baldwin, 1994), patterns of insect grazing (Gibberd et al., 1988), and plant competition (Edwards et al., 1992), it recently has included applied approaches stressing the usefulness of induced resistance as a tool in pest management programs (English-Loeb et al., 1993). In order to achieve their goals, both major foci of IR studies require a thorough knowledge of the already mentioned characteristics of IR.

This paper aims at characterizing the phenomenon of induced phytochemical responses in wheat, Triticum aestivum L., by examining the induction of its main natural products, the hydroxamic acids (4-hydroxy-1,4-benzoxazin-3ones, Figure 1) (Niemeyer, 1988), following a short-term infestation by the bird cherry-oat aphid, Rhopalosiphum padi (L.). Hydroxamic acids (Hx) are defensive metabolites typical of Gramineae (Niemeyer and Pérez, 1995). Hx are induced in wheat by aphid feeding, and this induction is affected by plant genotype (Niemeyer et al., 1989), aphid genotype (Gianoli et al., 1997), and environmental conditions (Gianoli and Niemeyer, 1996). In addition, constitutive accumulation of $\mathrm{Hx}$ reduced aphid infestation in the field but did not impose a cost in grain yield to wheat cultivars (Gianoli et al., 1996). In a similar vein, IR of $\mathrm{Hx}$ by aphid infestation on the wild wheat, $T$. uniaristatum, were shown to be not costly to the plant in terms of growth and survival (Gianoli and Niemeyer, 1997) and were characterized as localized, short-term IR (Gianoli and Niemeyer, 1998). In the present work, we attempt to determine the threshold of aphid load and the minimum time of aphid infestation required to elicit the

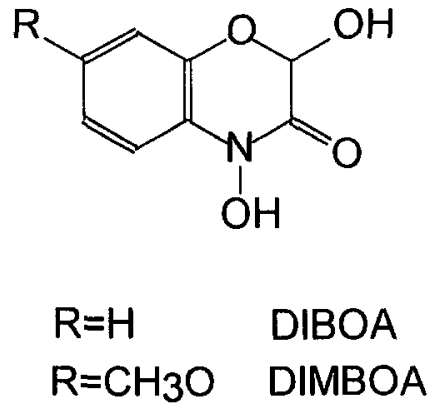

FIG. 1. Chemical structures of DIMBOA (2,4dihydroxy-7-methoxy-1,4-benzoxazin-3-one) and DIBOA (2,4-dihydroxy-1,4-benzoxazin-3-one), the main hydroxamic acid aglucones present in wheat extracts. 
induction of $\mathrm{Hx}$ in wheat seedlings. In addition, we gain insights into the modulation of such IR by biotic and abiotic factors by examining the effect of leaf age and nutrient supply on $\mathrm{Hx}$ induction. Results are discussed in the framework of the optimal defense theory (McKey, 1974; Rhoades 1979) and, in the experiment on the effect of nutrients, they are also tested against predictions of the carbon/nutrient theory (Bryant et al., 1983).

\section{METHODS AND MATERIALS}

Basic Experiment on Induction of $H x$. Seeds of T. aestivum cv. Paleta were obtained from INIA, Chile, and germinated in a growth chamber in individual plastic pots $(25 \mathrm{ml})$ filled with soil, and then grown in a growth chamber at $15^{\circ} \mathrm{C}$ and a photoperiod of $12 \mathrm{~L}: 12 \mathrm{D}$. When seedlings attained growth stage (gs) 11 (primary leaf fully unfolded, secondary leaf visible, Zadoks et al. 1974), each one was infested with 20 apterae of the bird cherry-oat aphid, Rhopalosiphum padi (L.) (second or third instar), confined in a clip cage attached to the primary leaf. Aphids came from a laboratory colony reared on oat seedlings at $20^{\circ} \mathrm{C}$ and a photoperiod of $12 \mathrm{~L}: 12 \mathrm{D}$. Empty clip cages were placed on control plants. After $48 \mathrm{hr}$ of infestation, aphids were removed from the infested seedlings and primary leaves of both control and treated plants were analyzed for Hx. No difference in fresh weight between control and infested leaves was found by the time of analysis of $\mathrm{Hx}$ in all the experiments performed (data not shown), thus allowing comparisons of concentrations of $\mathrm{Hx}$.

Threshold of Aphid Load. This experiment assessed the minimum load of aphids required to elicit the induction of $\mathrm{Hx}$ in the infested leaf (primary leaf). Densities of 2,10, and 25 aphids per clip cage were used in replicated basic experiments of induction. A LSD test following a one-way ANOVA was performed to examine differences of means among treatments $(N=8)$. This experiment was performed with late gs 12 seedlings (see below).

Duration of Infestation. Given that previous work showed $48 \mathrm{hr}$ of continuous aphid infestation as sufficient to generate IR of $\mathrm{Hx}$ in wheat (Niemeyer et al., 1989; Gianoli and Niemeyer, 1996), we evaluated whether $16 \mathrm{hr}$ of infestation could trigger IR as well. In order to determine whether a hypothetical lack of IR at the end of the 16-hr infestation could be due to either an insufficient stimulus or to a temporal constraint to the expression of the response, a treatment was included consisting of $16 \mathrm{hr}$ of infestation and $\mathrm{Hx}$ analysis $32 \mathrm{hr}$ later (to complete $48 \mathrm{hr}$ from the onset of infestation until chemical analysis). Comparisons of control and infested seedlings were performed for each treatment by one-way ANOVAs. Treatments were defined as 48-48, 16-16, and 16-48, where the first number refers to duration (hours) of aphid infestation and the 
second to the time elapsed from the onset of infestation to the analysis of $\mathrm{Hx}$ $(N=8)$.

Leaf Age. The basic experiment of induction was replicated at three different ontogenetic stages of the primary leaf related to three phenological stages of the seedling (Zadoks et al., 1974): gs 10 (primary leaf through coleoptile, seedling height 8-10 $\mathrm{cm}$ ), gs 11 (primary leaf unfolded and secondary leaf visible, $12-14 \mathrm{~cm}$ ) and gs 12 (primary leaf totally expanded, secondary leaf unfolded and tertiary leaf visible, $16-18 \mathrm{~cm}$ ). A two-way ANOVA for $\mathrm{Hx}$ concentration was performed, with leaf age and aphid infestation as fixed effects $(N=8$ for each treatment).

Nutrient Supply. The basic experiment of induction was replicated under two regimes of nutrient supply (high and low). Seeds were sown (October 15, $1996)$ in individual pots $(25 \mathrm{ml})$ filled with vermiculite and watered exclusively with $\mathrm{H}_{2} \mathrm{O}$ for five days; thereafter seedlings were subjected to either regimen of nutrient supply. Nutrient solutions were obtained from a master $\mathrm{N}: P: K$ aqueous solution $(30,20$, and $15 \mathrm{~g} /$ liter, respectively) diluted $1 / 100$ and $1 / 1000$ for the high and low nutrient treatment, respectively. Seedlings received $10 \mathrm{ml}$ of nutrient solution on October 21,24, 28, and 30. On October 30, the protocol of infestation was implemented, and $48 \mathrm{hr}$ later primary leaves were analyzed for $\mathrm{Hx}$ content. A two-way ANOVA for $\mathrm{Hx}$ concentration was performed, with nutrient regime and aphids as fixed effects ( $N=8$ for each treatment).

Chemical Analysis. Plant material was macerated with $1 \mathrm{ml} \mathrm{H}_{2} \mathrm{O}$, using a mortar and pestle. The aqueous extract was left at room temperature for $15 \mathrm{~min}$ and then taken to $\mathrm{pH} 3$ with $0.1 \mathrm{~N} \mathrm{H}_{3} \mathrm{PO}_{4}$. The extract was centrifuged at $13,000 \mathrm{~g}$ for $15 \mathrm{~min}$, and a $50-\mu \mathrm{l}$ aliquot of the supernatant was directly injected into a high-performance liquid chromatograph. An RP-100 Lichrospher-C18 column was used with a constant solvent flow of $1.5 \mathrm{ml} / \mathrm{min}$ and the following linear gradients between solvents $\mathrm{A}(\mathrm{MeOH})$ and $\mathrm{B}\left(0.5 \mathrm{ml} \mathrm{H}_{3} \mathrm{PO}_{4}\right.$ in 1 liter $\mathrm{H}_{2} \mathrm{O}$ ): 0-7 min, $30 \%$ A; 7-9 min, $100 \%$ A; 7-13 min, 30\% A. Detection of DIMBOA, the main $\mathrm{Hx}$ aglucone present, was performed at $263 \mathrm{~nm}$.

\section{RESULTS}

Twenty five was the minimum number of aphids per clip cage able to trigger an $\mathrm{Hx}$ accumulation in the infested leaf that was significantly different $(P<$ 0.05 , LSD-test following a one-way ANOVA) from the control treatment (Figure 2). The lower levels of $\mathrm{Hx}$ observed in control seedlings in comparison with those of other experiments (Figure 3 ) are due to the use of late gs 12 seedlings, which are in the decreasing phase of $\mathrm{Hx}$ accumulation (see Discussion).

It was found that $16 \mathrm{hr}$ of aphid infestation did not elicit an induction of $\mathrm{Hx}(P<0.05$, one-way ANOVA) even after a time-lag of $32 \mathrm{hr}$ prior to $\mathrm{Hx}$ 


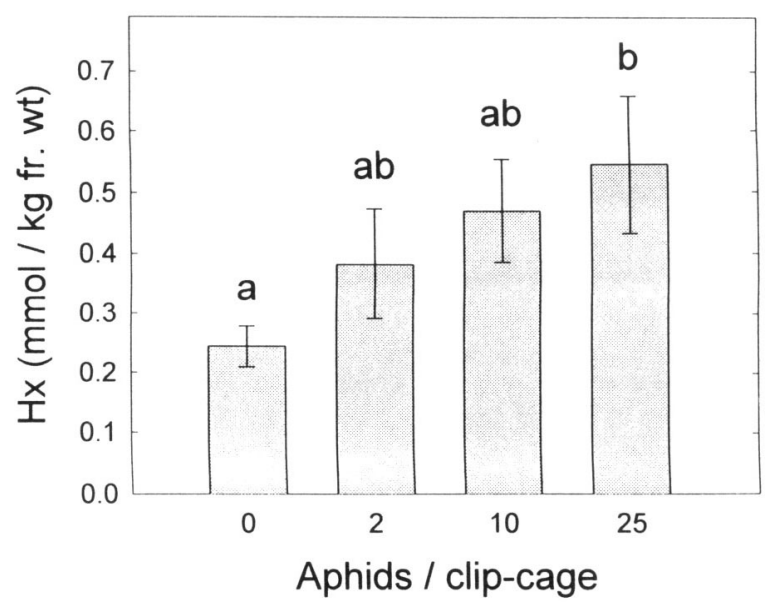

FIG. 2. Hydroxamic acid (Hx) content (mean $\pm \mathrm{SE}$, eight replicates) of the primary leaf of wheat seedlings after $48 \mathrm{hr}$ of infestation by different levels of aphid infestation. Means in columns sharing lowercase letters are not significantly different (LSD test following one-way ANOVA).

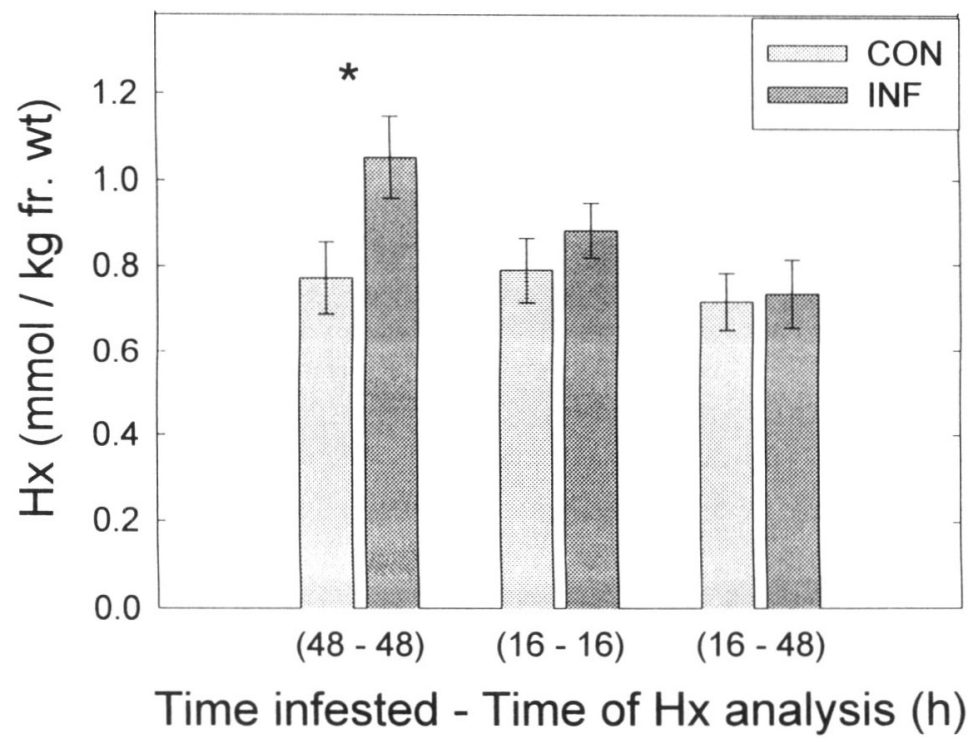

FIG. 3. Hydroxamic acid (Hx) content (mean \pm SE, eight replicates) of the primary leaf of aphid-infested (20 individuals) (INF) and noninfested control (CON) seedlings of wheat after different duration of infestation and time elapsed to $\mathrm{Hx}$ analysis since the onset of infestation. *Significant differences between control and infested plants at $P<$ 0.05 (one-way ANOVA). 
TAble 1. Effects of Aphid Infestation (20 ApHids for 48 hr) AND Leaf Age (AS Related to Seedling Growth Stage, gs) on Accumulation of Hydroxamic Acids in Primary leaf of Wheat Seedlings

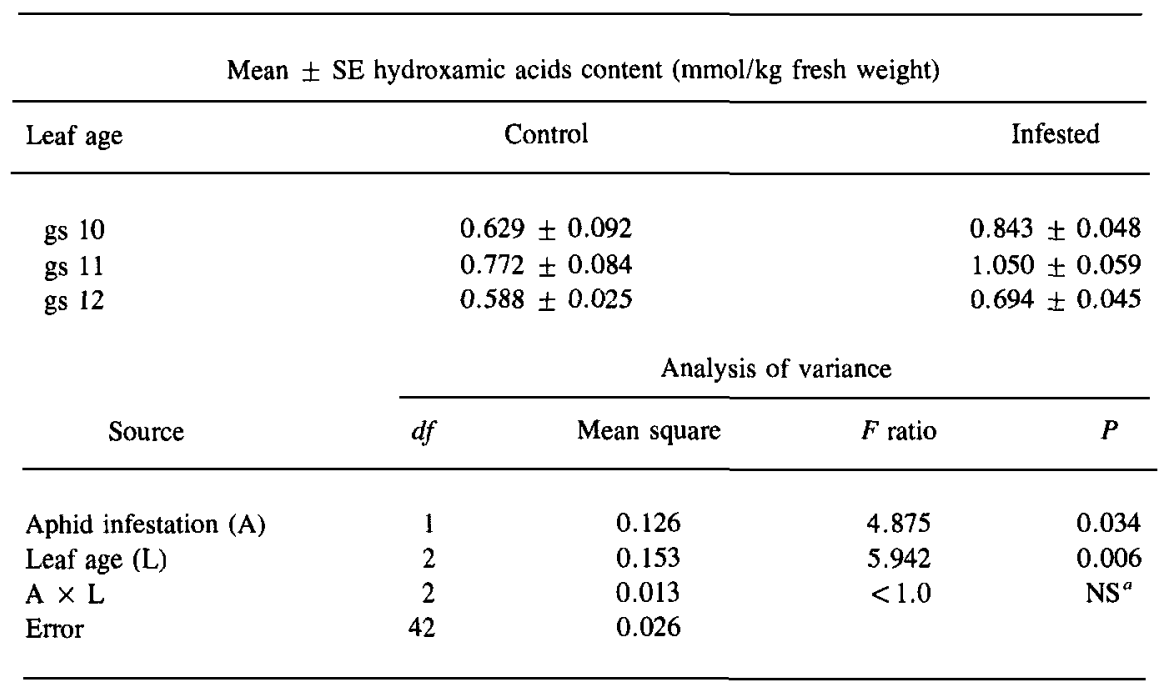

${ }^{a} \mathrm{NS}=$ not significant.

analysis. As expected, $48 \mathrm{hr}$ of infestation was needed to produce IR (Figure $3)$.

There was no effect of leaf age on $\mathrm{Hx}$ induction $(P>0.61$ for the interaction of effects: aphid $\times$ leaf age, two-way ANOVA) (Table 1). However, both aphid infestation and leaf age had significant effects on Hx levels of the primary leaf $(P<0.04$ and $P<0.01$, respectively; Table 1$)$. Higher Hx levels were found on infested plants, and an increase followed by a decrease of $\mathrm{Hx}$ was the pattern with leaf age (Table 1).

Nutrient supply regime did not affect $\mathrm{Hx}$ induction since the interaction of effects (aphid $\times$ nutrients) was not significant $(P>0.85$, two-way ANOVA) (Table 2). Aphid infestation did affect $\mathrm{Hx}$ accumulation on the primary leaf $(P$ $<0.025$ ), infested tissues containing higher $\mathrm{Hx}$ levels (Table 2). Higher nutrient input produced no increase in $\mathrm{Hx}$ levels, the effect being marginally nonsignificant $(P=0.061)$ (Table 2).

DISCUSSION

The intensity of herbivory has been considered to affect the magnitude of IR (Karban, 1991). In the present system, significant induction of $\mathrm{Hx}$ in wheat 


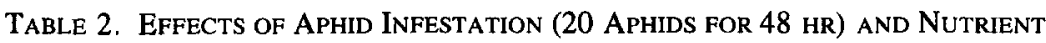
Supply Regime on Accumulation of Hydroxamic Acids in Primary leaf of Wheat SeEdLings

\begin{tabular}{|c|c|c|c|c|}
\hline \multicolumn{5}{|c|}{ Mean \pm SE hydroxamic acids content (mmol $/ \mathrm{kg}$ fresh weight) } \\
\hline Nutrients & \multicolumn{2}{|c|}{ Control } & \multicolumn{2}{|r|}{ Infested } \\
\hline Low & & 0.043 & & $\begin{array}{l}0.595 \pm 0.020 \\
0.686+0.042\end{array}$ \\
\hline \multirow[t]{2}{*}{ High } & & 0.052 & & $0.686 \pm 0.042$ \\
\hline & \multicolumn{4}{|c|}{ Analysis of variance } \\
\hline Source & $d f$ & Mean square & $F$ ratio & $P$ \\
\hline Aphid infestation (A) & 1 & 0.090 & 5.922 & 0.021 \\
\hline Nutrients $(\mathrm{N})$ & 1 & 0.058 & 3.800 & 0.061 \\
\hline$A \times \mathbf{N}$ & 1 & 0.001 & $<1.0$ & $\mathrm{NS}^{a}$ \\
\hline Error & 28 & 0.015 & & \\
\hline
\end{tabular}

${ }^{a} \mathrm{NS}=$ not significant

seedlings was restricted to the higher aphid load tested ( 25 individuals per clip cage) and did not appear following 16-hr infestations. Lower aphid densities did not increase $\mathrm{Hx}$ levels in infested tissues. Thus, an infestation of 25 aphids (or 20, as this and previous work reported) for $48 \mathrm{hr}$ seems to be the threshold for eliciting IR of $\mathrm{Hx}$ in wheat seedlings. Interestingly, a similar work on aphidinduced $\mathrm{Hx}$ in a wild wheat showed that a load of 10 aphids (for $48 \mathrm{hr}$ ) was enough to obtain IR and, furthermore, induced Hx levels remained constant following greater densities of infestation (Gianoli and Niemeyer, 1998). It may be that cultivated wheat, subjected to artificial selection oriented towards agronomic features, has suffered a loss in its capacity to react readily to cues of herbivore attack by increasing the concentration of secondary metabolites. Alternatively, different "sensitivities" to aphid infestation may be a consequence of differences in tolerance, i.e., the capacity to recover after herbivory. Thus, plants with greater tolerance levels could delay the allocation of defenses to attacked tissues until the degree of damage threatened its fitness, hence saving resources to devote to growth or reproduction (see Zangerl and Bazzaz, 1992).

Leaf age is a factor usually overlooked in IR studies (Coleman and Jones, 1991). Contrary to previous reports on indole alkaloids (Frischknecht et al., 1987) and phenols (Hartley and Firn, 1989), and in accordance with recent work on furanocoumarins (Zangerl and Berenbaum, 1995), we found that age of the 
infested leaf did not affect induction of Hx. Both aphid infestation and leaf age, however, had singly a significant effect on $\mathrm{Hx}$ levels of the primary leaf. The aphid effect was expected as $\mathrm{Hx}$ are inducible; likewise, an effect of leaf age was also expected since the dynamics of $\mathrm{Hx}$ accumulation in wheat seedlings is highly sensitive to age (Argandoña et al., 1981). Thus, the pattern of $\mathrm{Hx}$ accumulation for the whole plant as well as for any single leaf consists of an initial increase until reaching an early peak and a steady decrease thereafter. As can be seen (Table 1), the seedling growth stages (gs) utilized in this experiment fall in the upward-maximum-downward part of the curve of $\mathrm{Hx}$ accumulation.

The optimal defense (OD) theory (McKey, 1974; Rhoades, 1979) would predict that younger-and hence more valuable-plant parts receive better protection by enhanced defense allocation (see Bryant and Julkunen-Tiitto, 1995). To some extent this was the case for the primary leaf of wheat seedlings if constitutive $\mathrm{Hx}$ levels are considered (Table 1). However, as shown by the statistical analysis performed, this leaf showed comparable degrees of Hx induction for the three growth stages evaluated. This lack of effect of leaf age may be an artifact of the limited range of seedling phenological stages studied. Older phenological stages and hence lower $\mathrm{Hx}$ constitutive levels (in accordance with the dynamics of accumulation) could constitute a scenario in which greater levels of induced $\mathrm{Hx}$ could be produced in order to achieve a better protection.

Results obtained showed that nutrient availability did not affect induction of $\mathrm{Hx}$ by aphid infestation. Similar results were obtained with lupine alkaloids (Johnson et al., 1989), tobacco alkaloids (Ohnmeiss and Baldwin, 1994), and furanocoumarins (Zangerl and Berenbaum, 1995). As expected, aphid infestation affected $\mathrm{Hx}$ accumulation. As was reported for corn seedlings (Manuwoto and Scriber, 1985), nutrient supply regime affected overall $\mathrm{Hx}$ accumulation in wheat seedlings, but its effect was not significant. Regarding the close relationship between available nitrogen in the substrate and concentration of $\mathrm{N}$-based compounds in wheat (Kowalski and Visser, 1987) and given that Hx may be classified as N-based secondary metabolites (Figure 1) and that nutrient solution was predominantly nitrogen (55\%), this effect was not surprising. Nonetheless, in view of this fact, it is reasonable to expect a higher induction in the highnutrient regime due to the greater availability of nitrogen; however, this did not occur. A rationalization for these results may be produced by examining general theories of plant defense allocation.

OD theory predicts enhanced allocation of (induced) defenses to tissues with high fitness value, costly to replace, and/or with high probability of attack. This allocation should reflect the costs and benefits of investing those resources in defense instead of in growth or reproduction. On the other hand, carbon/ nutrient $(\mathrm{C} / \mathrm{N})$ theory (Bryant et al., 1983) would consider production of induced defenses limited by plant requirements of either $\mathrm{C}$-based or $\mathrm{N}$-based compounds 
for growth and in relation to environmental conditions. Thus, occurrence of IR (according to whether the defenses are $\mathrm{C}$-based or N-based) would be conditioned to internal imbalances in either type of compound and to the effect of herbivory on the $\mathrm{C} / \mathrm{N}$ ratio in the tissue concerned. Given that both theories address the relationship of defense to growth, it is important to point out that growth of the infested primary leaf did not differ from that of the control in either nutrient treatment (data not shown).

Our system consisted of: (1) plants treated with different levels of $N$ in the substrate; (2) a phloem-feeder that depletes proportionally more C-based compounds than N-based ones (see Hayashi and Chino, 1986), i.e., relatively increases available $\mathrm{N}$; and (3) a $\mathrm{N}$-based natural product. Therefore, $\mathrm{C} / \mathrm{N}$ theory would predict a higher level of induction of $\mathrm{Hx}$ in the high-nutrient treatment. This prediction was not supported by the results obtained. Altematively, from the standpoint of OD theory, a more complex scenario may be conceived. On the one hand, a greater $\mathrm{N}$ budget would allow an enhanced allocation to $\mathrm{N}$-based induced defenses without major penalties in growth for such resource investment. Then a higher level of induction of $\mathrm{Hx}$ in the high-nutrient treatment may be predicted. On the other hand, tissue of plants in richer habitats is of lesser value since its replacement is less costly to the plant and hence should receive less chemical protection than a comparable tissue in a plant growing in a poor habitat. Although the expression of such an advantage in growth and tissue replacement was not evident in our experiment, it should appear with longer periods of evaluation. This view would lead one to expect a lower level of induction of $\mathrm{Hx}$ in the high-nutrient treatment. We speculate that under the experimental conditions of this study both trends occurred, and hence the outcome was a lack of effect of nutrients on $\mathrm{Hx}$ induction. Further studies involving longer evaluations and including whole-plant allocation patterns will confirm or reject this preliminary observation.

Finally, another point relevant to the lack of effect of nutrients on $\mathrm{Hx}$ induction concerns the mechanism of induction. Whether $\mathrm{Hx}$ are synthesized in situ or transported to the attacked tissue would determine the relative importance of a surplus of nitrogen for $\mathrm{Hx}$ induction, since in situ synthesis is expected to be more sensitive to resource availability than translocation. Since aphid-induced $\mathrm{Hx}$ in the primary leaf of a wild wheat was shown to be a consequence of translocation from the stem (Gianoli and Niemeyer, 1997), it is likely that a similar process is operating in the present system, hence supporting the pattern found.

The characteristics of the induction of $\mathrm{Hx}$ by aphid infestation in wheat seedlings were determined in terms of the minimal stimuli able to generate it and the biotic as well as abiotic constraints to its expression. Although evaluations were restricted to a limited set of conditions, they represent a first approach 
to the knowledge of such a complex trait as inducible plant defenses and thereby provide valuable information to both theoretical and applied research projects. The phenomenon of $\mathrm{Hx}$ induction in wheat seedlings appeared to be dependent on initial stimulus conditions (duration and magnitude of the infestation) but insensitive to biotic (leaf age) as well as abiotic (nutrient supply regime) factors. Results obtained were shown to be partially in accordance with OD theory predictions.

Acknowledgments - We thank L. Kirchgessner for technical assistance. This work was supported by the Presidential Chair in Sciences awarded to H.M.N., a grant from FONDECYT (1961035), the International Program in the Chemical Sciences at Uppsala University, and the Swedish Department for Research Cooperation, SAREC. E.G. was supported by a Latin American Plant Sciences Network fellowship (93-M8) during part of the development of this work.

\section{REFERENCES}

Argandoña, V. H., Niemeyer, H. M., and Corcuera, L. J. 1981. Effect of content and distribution of hydroxamic acids in wheat on infestation by Schizaphis graminum. Phytochemistry 20:673-676.

BALDWIN, I. T. 1989. The mechanism of damage-induced alkaloids in wild tobacco. J. Chem. Ecol. $15: 1661-1680$.

BALDwin, I. T., Sims, C, L., and KEAN, S. E. 1990. The reproductive consequences associated with inducible alkaloidal responses in wild tobacco. Ecology 71:252-262.

BRYANT, J. P., Chapin, F. S., and KLEIN, D. R. 1983. Carbon/nutrient balance of boreal plants in relation to vertebrate herbivory. Oikos 40:357-368.

Bryant, J. P., and Julkunen-TitTto, R. 1995. Ontogenic development of chemical defense by seedling resin birch: energy cost of defense production. J. Chem. Ecol. 21:883-896.

COLEMAN, J. S., and JONES, C. G. 1991. A phytocentric perspective of phytochemical induction by herbivores, pp. 3-46, in D. W. Tallamy and M. J. Raupp (eds.). Phytochemical Induction by Herbivores. John Wiley \& Sons, New York.

EDWARdS, P. J., WratTen, S. D., and PARKer, E. A. 1992. The ecological significance of woundinduced changes in plants: insect grazing and plant competition. Oecologia 91:266-272.

English-Loeb, G. M., Karban, R., and Hougen-EITZman, D. 1993. Direct and indirect competition between spider mites feeding on grapes. Ecol. Appl. 3:699-707.

FrischkNeCht, P. M., BÄTTIG, M., and BaumanN, T. W. 1987. Effect of drought and wounding stress on indole alkaloid formation in Catharanthus roseus. Phytochemistry 26:707-710.

GiANOLI, E., and NiEMEYER, H, M. 1996. Environmental effects on the induction of wheat chemical defences by aphid infestation. Oecologia 107:549-552.

GiANOL, E., and NiEMEYeR, H. M. 1997. Lack of costs of herbivory-induced defenses in a wild wheat. Integration of physiological and ecological approaches. Oikos 80, In press.

Gianoli, E., and NiemeYER, H. M. 1998. Allocation of herbivory-induced hydroxamic acids in the wild wheat, Triticum uniaristatum. Chemoecology In press.

GianOl, E., PAPp, M., and NiemeYer, H. M. 1996. Costs and benefits of hydroxamic acids-related resistance in winter wheat against the bird cherry-oat aphid, Rhopalosiphum padi (L.) Ann. Appl. Biol. 129:83-90.

Gianoli, E., Caillaud, C. M., Chaubet, B., Di Pietro, J. P., and Niemeyer, H. M. 1997. Variability in grain aphid Sitobion avenae (F.) (Homoptera: Aphididae) performance and aphidinduced phytochemical responses in wheat. Environ. Entomol. 26:638-641. 
GibBerd, R., EdWARDS, P. J. and WRATten, S. D. 1988. Wound-induced changes in the acceptability of tree foliage to Lepidoptera: within-leaf effects. Oikos 51:43-47.

Hartley, S. E., and Firn, R. D. 1989. Phenolic biosynthesis, leaf damage and insect herbivory in birch (Betula pendula). J. Chem. Ecol. 15:275-283.

HAYaSHI, H., and ChINo, M. 1986. Collection of pure phloem sap from wheat and its chemical composition. Plant Cell Physiol. 27:1387-1393.

Johnson, N. D., Rigney, L. P., and Bentley, B. L. 1989. Short-term induction of alkaloid production in lupines. Differences between $\mathrm{N}_{2}$-fixing and nitrogen-limited plants. J. Chem. Ecol. 15:2425-2434.

KARBAN, R. 1991. Inducible resistance in agricultural systems, pp. 402-420, in D. W. Tallamy and M. J. Raupp (eds.). Phytochemical Induction by Herbivores. John Wiley \& Sons, New York.

KowALSKI, R., and VISSER, P. E. 1987. Changes of free aminoacids in the leaves of Triticum aestivum and their implications for the assessment of plant/insect interactions. J. Plant Dis. Prot. 94:161-168.

MANUwoto, S., and SCRIBER, J. M. 1985. Consumption of experimentally altered com by southern armyworm: Iron, nitrogen, and cyclic hydroxamates. J. Chem. Ecol. 11:1469-1483.

MCKeY, D. 1974. Adaptive patterns in alkaloid physiology. Am. Nat. 108:305-320.

NiEMEYER, H. M. 1988. Hydroxamic acids (4-hydroxy-1,4-benzoxazin-3-ones), defence chemicals in the Gramineae. Phytochemistry 27:3349-3358.

Niemeyer, H. M., and PEREZ, F. J. 1995. Potential of hydroxamic acids in the control of cereal pests, diseases and weeds, pp. 260-269, in Inderjit, K. M. M. Dakshini, and F. A. Einhellig (eds.). Allelopathy. Organisms, Processes, and Applications. ACS Symposium Series 582, Washington, D.C.

Niemeyer, H. M., Pesel, E., Copaja, S. V., Bravo, H. R., Franke, S., and Francke, W. 1989. Changes in hydroxamic acids levels of wheat plants induced by aphid feeding. Phytochemistry 28:447-449.

OhNmeIss, T. E., and BALDWIN, I. T. 1994. The allometry of nitrogen allocation to growth and an inducible defense under nitrogen-limited growth. Ecology 75:995-1002.

RHOADES, D. F. 1979. Evolution of plant chemical defense against herbivores, pp. 3-54, in G. A. Rosenthal and D. H. Janzen (eds.). Herbivores: Their Interaction with Secondary Plant Metabolites. Academic Press, Orlando.

Zadoks, J. C., Chang, T. T., and ConsaK, C. F. 1974. A decimal code for the growth stage of cereals. Weed Res. 14:415-421.

ZANGERL, A. R. 1990. Furanocoumarin induction in wild parsnip: Evidence for an induced defense against herbivores. Ecology 71:1926-1932.

ZANGerL, A. R., and BAZZAZ, F. A. 1992. Theory and pattern in plant defense allocation, pp. 363-391, in R. S. Fritz, and E. L. Simms (eds.). Plant Resistance to Herbivores and Pathogens. Ecology, Evolution and Genetics. University of Chicago Press, Chicago.

ZANGERL, A. R., and BERENBAUM, M. R. 1995. Spatial, temporal and environmental limits on xanthotoxin induction in wild parsnip foliage. Chemoecology 5/6:37-42. 